\title{
Causal Relations of Factors Representing the Elderly Independence in Doing Activities of Daily Livings Using S3C-Latent Algorithm
}

\author{
Nurhaeka Tou ${ }^{1}$, Ridho Rahmadi ${ }^{1}$, Christantie Effendy. ${ }^{2}$ * \\ Universitas Islam Indonesia Indonesia \\ Departement of Medical Surgical Nursing, Faculty of Medicine, Public Health, and Nursing, University Gadjah Madah Indonesia \\ ${ }^{2}$ christantie@ugm.ac.id ${ }^{*}$ \\ * corresponding author
}

Article history:

Received 010-12-2020

Revised 08-01-2021

Accepted 19-07-2021

Keywords:

ADLs

Causal Relationship

Elderly

Indonesia

S3C-latent

The growth of the elderly population in Indonesia from year to year has always increased, followed by the problem of decreasing physical strength and psychological health of the elderly. These problems can affect the independence of the elderly in ADL. In previous studies, various factors affect independence in ADLs such as cognitive, psychological, economic, nutrition, and health. However, general, these studies only focus on predictive analysis or correlation of variables, and to our knowledge no research has attempted to identify the causal relationships among factors representing the elderly independence. Therefore, this research aims to estimate the causal mechanisms between factors which influence the independence of the elderly in ADLs using a casual method called S3C-Latent. In this research, we found both causal and associative relationships between the factors.The ADLs were influenced by cognitive, psychological, nutritional, and health factors and gender which satisfies $\pi_{\text {sel }}$ with reliability score $(0.61 ; 0.61 ; 1.00$; $0.65 ; 0.70 ;$ respectively). Cognitive factors associated with psychological, economic, nutrition, and health which satisfies $\pi_{\text {sel }}$ with reliability score $(0.77 ; 1.00 ; 1.00 ; 0.64$; respectively $)$. Furthermore, psychological factors associated with economy, nutrition, and health which satisfies $\pi_{s e l}$ with reliability score ( 0.77 ; 0.95 ; 0.63 ; respectively). Besides, economic factors were found to be associated with nutrition and health which satisfies $\pi_{\text {sel }}$ with reliability score ( 0.86 ; 0.75 ; respectively ) and nutrition with health which satisfies $\pi_{\text {sel }}$ with reliability score 0.64 . The last association was found between nutritional factors and gender which satisfies $\pi_{\text {sel }}$ with reliability score 0.76 . The estimated causal model is expected to be a scientific reference for the health providers as well asthe caregivers who focus on the elderly independence on ADLs.

Copyright @ 2017 International Journal of Artificial Intelegence Research. All rights reserved.

\section{Introduction}

Advances in technology in the health sector can improve the demographic condition of a country. This is reflected on the increasing of life expectancy [1]. Indonesia is one of the countries which has experienced an increase in life expectancy. In 2015-2020, the life expectancy of the Indonesian population reaches 71 years. This increase has an impact on the growing number of the elderly population. The elderly population in Indonesia currently ranks 4th in the world. The number of elderly people in Indonesia in 2019 reached 25.66 million people, which is equal to 9.60 percent of the total population in Indonesia and is expected to continue to increase until 2045 [2]. 
According to WHO, in 2020 the number of people over 60 years old exceeds the number of children under 5 years of age [3]. The increase in the number of elderly is influenced by the decrease in fertility (birth) and mortality (death), and the increase in life expectancy which results in changes in the overall population structure [2][4]. The increasing number of elderly people can cause various complex problems for the elderly themselves as well as for families and communities [5]. People who have entered the elderly phase will experience a decreased social role which can cause suffering and increase the likelihood of isolation and feelings of loneliness [6]. Thus, this event can be a threat to the elderly, society, or the government, because it can lead to a decrease in the productivity of the elderly [7].

The process of getting old can cause the elderly to experience physical and mental changes, which can affect their economic, health, and social conditions [8]. These changes greatly affect the independence of the elderly in carrying out their daily activities[1]. Thus, it can lead to dependence of the elderly on other people and reduce the productivity of the elderly [7]. In 2019 the dependence of the elderly reached 15.01 percent or it can be said that 100 productive people must support 15 elderly people [2]. The high ratio can be a problem for society and shows that the independence and welfare of the elderly are not maintained [9]. Therefore, to increase the independence of the elderly and maintain the quality of life of the elderly, it is necessary to make proper interventions according to the factors that affect ADLs so that their prevention can be carried out regularly and efficiently.

The research on factors that influence the independence of the elderly in doing ADLs have been done before. The research of Pei et al.[10] who used industrial instruments and brief nutritional estimates showed that factors which had a significant impact on ADL were stroke frequency, stroke type, nutritional status, financial status, and age. Furthermore, in Mlinac \& Feng's [11] research of independence in doing ADLs, several factors were condutcted, namely cognitive, motor, and perceptual abilities. Then, in Kodri \& Rahmayati's [12] research which used the cross-sectional method, the chi-square test showed that health, social and family support factors could affect the independence of the elderly in ADLs. Another research conducted by Marlita et al. [13], using descriptive analysis, showed if the independence of the elderly in ADL is significantly related to factors of age, physiological health, cognitive function, and psychosocial function. Meanwhile, in Wahyuni's research, various factors were found to affect the independence of the elderly in ADLs, namely cognitive factors, health factors, nutritional factors, economic factors, psychological factors, gender, and marital status [14]. However, the study only focuses on correlation analysis, which only shows the closeness of the relationship between one variable and another. Correlation analysis cannot predict causality, although it can identify associations [9]. So, it has not been able to answer the question of, how are the causal mechanisms underlying these factors?

Causal modeling is a representation of the fundamental interactions between factors in a problem context, and is of importance in many scientific domains [15]. To provide an appropriate and efficient treatment for the independence of the elderly, doctors and health workers need to understand how the independence of ADLs originates and impacts[16]. Hence, we need to understand the causal mechanisms among the factors associated with ADLs, that is, cognitive factors, psychological factors, economic factors, nutritional factors, health factors, independence factors, and gender [14]. Understanding the causal relationship between these factors is very important, e.g., so that the health workers can be more focused on important factors in providing therapy to the elderly. I in this research, therefore, we intend to model the causal relationship of the factors leading to elderly independence in ADLs. The purpose of this research was to identify the causal relationship of the factors that influence the independence of the elderly in doing ADLs. This research is expected to a scientific reference for researchers, health workers, and elderly cadres in making decisions and designing appropriate and efficient interventions for elderly patients. 
Specifically, our research uses a causal algorithm called Stable Specification Search for CrossSectional Data with Latent Variables (S3C-Latent). This algorithm looks for stable and simple causal relationship structures (in the context of complexity). Technically, S3C-Latent combines the concept of stability selection to determine a stable causal structure, Non-dominated Sorting Genetic Algorithm-II (NSGA-II) to find optimal causal models based on conflicting criteria, and Structural Equation Models (SEMs) to represent causal models with latent variables [16].

\section{Research Method}

\section{A. Literature Research}

This research stage starts from reviewing and understanding the findings from previous studies to be used as a basis for research to be carried out. This research uses data from the Health and Demographic Surveillance System (HDSS), Universitas Gadjah Mada. The data were collected by he HDSS team from September-November 2018.

The data set used in this research consists of 464 respondents. The data retrieval process begins by sending the data usage request procedure to HDSS. After obtaining approval from the head of HDSS research, the researcher obtained the requested data. The data collection was carried out using several research instruments as follows.

Tabel 1. Research Questionnaire

\begin{tabular}{|l|l|c|c|}
\hline \multicolumn{1}{|c|}{ Factors } & \multicolumn{1}{c|}{$\begin{array}{c}\text { Type of } \\
\text { Questionnaire }\end{array}$} & Respondents & $\begin{array}{c}\text { Previous } \\
\text { Researchers }\end{array}$ \\
\cline { 1 - 3 } Kemandirian ADLs & ADLs & 464 & \\
\hline Cognitove & MMSE & 464 & \\
\cline { 1 - 3 } Psychology & GDS \& CSDD & 464 & \multirow{2}{*}{ [14] } \\
\cline { 1 - 3 } Economy & FMBS & 464 & \\
\cline { 1 - 2 } Nutrition & MNA & 464 & \\
\hline Health & HDSS & 464 & \\
\hline
\end{tabular}

Based on This research stage starts from reviewing and understanding the findings from previous studies to be used as a basis for research to be carried out. This research uses data from the Health and Demographic Surveillance System (HDSS), Universitas Gadjah Mada. The data were collected by he HDSS team from September-November 2018.

The data set used in this research consists of 464 respondents. The data retrieval process begins by sending the data usage request procedure to HDSS. After obtaining approval from the head of HDSS research, the researcher obtained the requested data. The data collection was carried out using several research instruments as follows.

Tabel 1. Research, the ADLs questionnaire for ADLs independence factors [17], the MiniMental State Examination (MMSE) questionnaire for cognitive factors [18], the Geriatric Depression Scale (GDS) questionnaire for psychological factors that are not dementia, and the Cornell Scale for Depression in Dementia (CSDD) questionnaire for respondents dementia [19]. Furthermore, the Financial Management Behavior Scale (FMBS) questionnaire for economic factors [20], the Mini Nutritional Assessment (MNA) questionnaire for nutritional factors [21], and the HDSS questionnaire for health factors [14].

This research was approved by the Ethic Committee of Faculty of Medicine, Public Health and Nursing, Universitas Gadjah Mada (Number Ref.No.KE/FK/0715/EC/2020). This research focuses on 7 factors, namely cognitive, psychological, economic, nutrition, health, independence of ADLs, and gender. The selection of these factors is based on the researchers focus which stems from several previous studies. 
The choice of cognitive factors in this research was because decreased memory could affect the elderly's ability to recognize people around them, feel depressed, be more sensitive, and have an impact on decreasing the quality of life of the elderly. This decrease in quality of life causes the elderly to be less independent in their daily activities [22]. Besides, a decrease in the mental condition of the elderly can also cause physical changes, thoughts, feelings, and behaviors that can interfere with their daily activities. When viewed based on the characteristics of respondents in previous studies, the female gender dominates. This also underlies the choice of psychological factors in this research, because the number of elderly women who experience depression is more dominant than men [23]. This is because, biological changes, especially hormonal and psychosocial, women have more roles to play, which can become stressors and trigger depression [22]

Naturally, the older a person gets, the more his physical health decreases. This is usually marked by the onset of various diseases, decreased body function, body balance, and the risk of falling which can interfere with the activities of the elderly in their daily activities. Therefore, in this research, health factors were chosen as one of the factors that affect the independence of the elderly [24].

In the elderly, aging has to do with aspects that exist in nutritional factors that will affect the quality of life of the elderly. These aspects include the sense of smell and taste, the ability to chew, swallow food, and digestion and intestines. Besides, malnutrition and lack of physical activity can lead to decreased appetite and the inability to perform ADLs [25]. This is what underlies the selection of nutritional factors in this research.

Furthermore, the selection of economic factors in this research, because the elderly have financial management capabilities related to meeting clothing, food, health, or social needs. With good financial management skills, the elderly will be able to make decisions about a good lifestyle and be able to meet their daily needs independently [14].

Apart from the six factors above, we add one demographic factor, namely gender. the choice of gender factors is due to a significant relationship with several factors such as psychological, health, and cognitive. In research Yeni Kartika [26], shows that men have a higher level of hypertension than women however have a high level of alertness lower against hypertension than a woman. Besides, gender is related to psychology, where the number of elderly women who experience depression is more dominant than the male gender [23]. Then in research by Muller-Gerards et al. [27], it was shown that men Have a higher chance of experiencing mild cognitive than women. In line with the domain of interest in this research, we want to look at the causal modeling of the independent factors of the elderly in gender groups.

\section{B. Data Preprocessing}

The second stage is data pre-processing, which is carried out to check the completeness of the dataset before analyzing the data such as editing, coding, checking for missing values, data inconsistencies or data redundancies, and data cleaning. The result of this stage is a dataset that is ready to be computed.

\section{Causal Modelling}

The next stage in this research is causal modeling. Causal modeling is a model to understand the mechanisms underlying the variables in the data that are interrelated with each other in terms of causal relationships [16]. Causal modeling is performed using the S3C-Latent method implemented in an R package (https://github.com/rahmarid/S3C-Latent). Data computation is carried out on the server computer with parameter setting and parallel computation. We used the Hanabi server for data computing with specifications that include, 80 Cores, 250GB RAM, 4GPU, Jupyter GUI and console, as well as a personal environment. The programming language used in this research is $\mathrm{R}$ version 4.0.0. Apart from supporting the $\mathrm{R}$ programming language, the server also supports the Python programming language version 3.7 The following is an explanation of the S3C and S3CLatent methods. 


\section{1) Stable Specification Search}

S3C is a causal method used on observed variables or indicators with SEM (Structural Equation Model) modeling. S3C has a stable and simple structure. S3C method is a causal modeling method that combines SEM, NSGA-II, and stability selection. From the test results, S3C relatively outperforms other causal methods [16]. S3C illustration can be seen in

Fig 1. The Stable Specification Search (S3C) Method

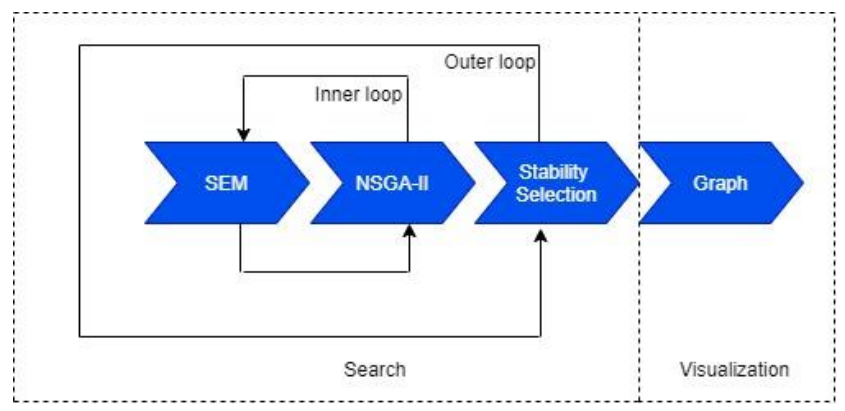

Fig 1. The Stable Specification Search (S3C) Method

The S3C method consists of two phases, namely the search phase and the visualization phase. The search phase is an iterative process using an inner loop and an outer loop that combines SEM, NSGA-II, and Stability Selection to search for a model that is stable and has a simple model complexity. The visualization phase is used to present the relevant relationships of the causal model for easy understanding [16].

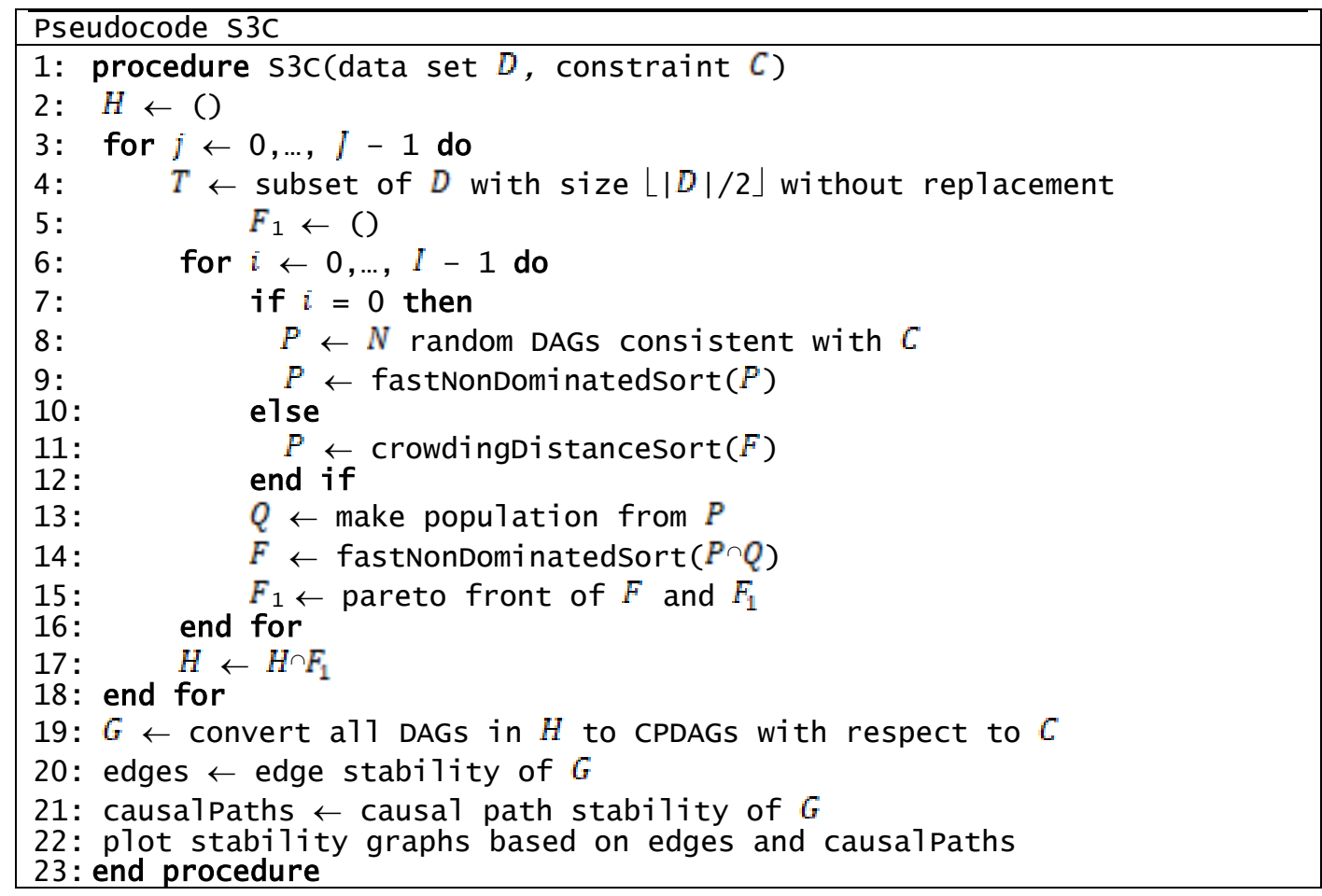

Based on pseudocode S3C, it can seen that lines 3-18 represent the outer loop, which randomly takes a sample $T$ dari $D$ of size $\lfloor|D| / 2\rfloor$ (line 4). Lines 6-16 represent the inner loop by running to get the Pareto front. In the inner loop, it starts by forming a sized population $P$ size $N$, initially randomly or can be taken from the previous population using crowding distance sorting (lines 7- 
12). The model is represented by a binary vector $\{0,1\}$ which indicates the existence of multiple $\operatorname{arcs} \mathrm{X} \rightarrow \mathrm{Y}$.

The 13 line forms a new population $Q$ by manipulating $P$ it using binary tournament selection, one-point crossover, and one-bit flip mutations compatible with binary representations. a one-point crossover takes two models from $M_{\text {pool }}$ and exchanges the data after the crossover point (center). A one-bit flip mutation flips each bit according to a predetermined rate. Line 14 combines $P$ and $Q$ sorts them using fast non-dominated sorting, resulting in a model set of fronts $F$. Line 15 updates Pareto Fronts on $F_{1}$.

After running in the inner loop (rows 6-16), the results are stored in $H$ (row 17). After the iteration $l, H$ it $l$ contains the Pareto front. is the number of inner loop iterations, is the number of outer loop iterations. In lines, 19-22 convert $I$ the Pareto front $H$ from DAG to CPDAG using the consDAG2Cpdag algorithm and then compute the edge and causal path stability graphs. Stability graphs are considered the main product of S3C, but can also be visualized as graphs with nodes and edges.

\section{2) S3C-Latent}

S3C-Latent is an extension of the S3C method. The difference between S3C and S3C-Latent lies in data usage. S3C-Latent is used to model cause and effect relationships between latent variables. Latent variables are variables that cannot be measured directly but can be represented through relevant indicators. Therefore, in representing the model the results will be different from S3C [16]. Here's the S3C-Latent pseudocode:

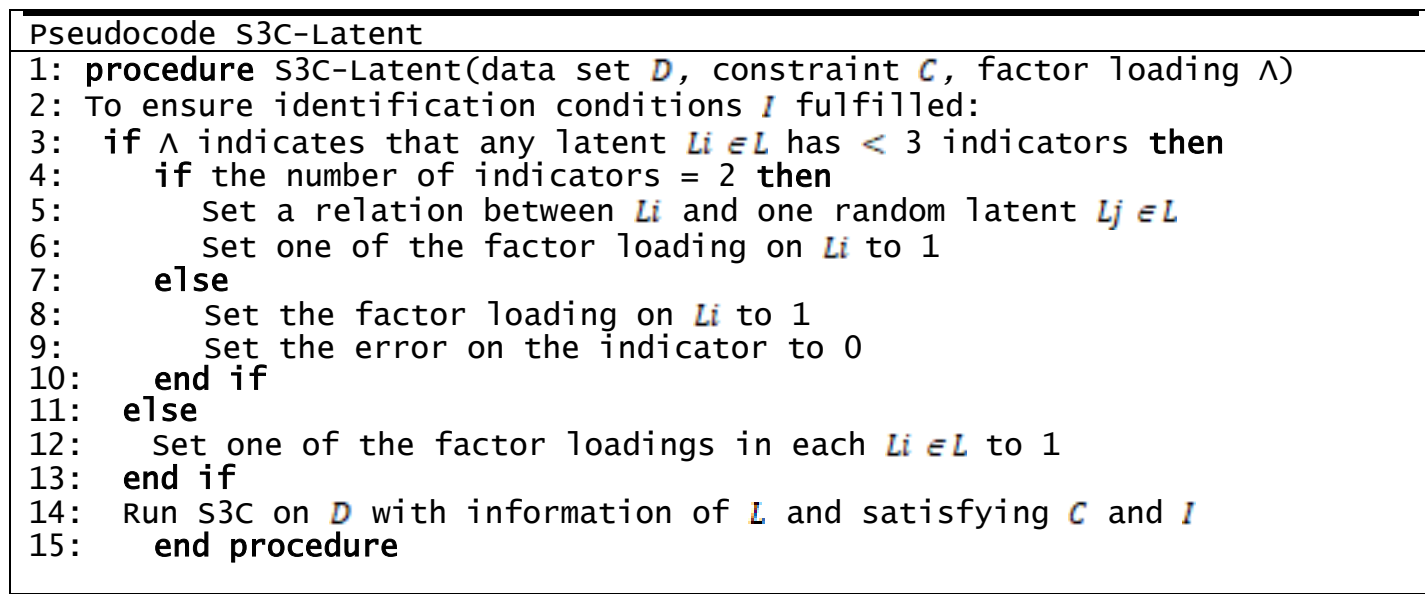

Based on S3C-Latent Pseudocode, it can be seen that $D$ it is a data set, $C$ is prior knowledge, and $\Lambda$ is a matrix containing latent variables. Lines 2 to 12 show information that the model identification conditions have been met. In the 3rd line, observe whether the latent variable $L i \in L$ has less than 3 indicators. If there is a case where it has 2 indicators, S3C-Latent will determine the relationship between the latent variable $L i$ and the latent variable which is randomly selected $L j \in L$ (which can $L i$ be a causal variable) and will fix one of the factors to become a unity. However, if there is only 1 indicator, S3C-Latent will process the factor $L i$ into 1 and will set the error on the 0 indicators as in the 8th and 9th lines.

The 12 line indicates that it will be applied if all latent variables have at least 3 indicators. Whereas the 13th line will run S3C on the data set $(D)$ with the latent variable information $L$ that has met all the conditions on $C$ and also the model identification conditions on $I$. If any constraints on and have been met, S3C-Latent will ensure that the SEM generated and defined will be consistent based on prior knowledge $(C)$.

\section{Evaluation}

The fourth stage of this research is evaluation. At this stage we involve health workers to evaluate and interpret the models that have been obtained. Technically, we did the validation by 
conducting an interview and FGD with the involvement of an expert in Nursing field. The evaluation results show that the model obtained rationally can be accepted medically.

\section{E. Dissemination}

The last stage, of this research is dissemination. At this stage the research results obtained are implemented into a web tool designed using R Shiny programming. Thus, it can be used by health workers as an easy-to-understand reference in providing appropriate interventions in elderly care.

\section{Result and Discussion}

\section{A. Result}

The demographic characteristics of research subjects were described based on age, sex, ethnicity, marital status, location of residence, and living together. Tabel 2. Demographic Characteristics of Respondents, shows the majority of respondents in this research were female (55.2\%) and most of them had entered the elderly (60-74 years) as many as $73.9 \%$. The respondents who were married in this research were $61.6 \%$ and most of them lived with their families $(88.1 \%)$. Besides, the respondents in this research lived in urban areas of $78.4 \%$, had low education $(77.8 \%)$ and the dominant respondents came from the Javanese ethnicity (98.7\%).

Tabel 2. Demographic Characteristics of Respondents $(n=464)$

\begin{tabular}{llcc}
\hline Characteristics & \multicolumn{1}{c}{ Indicator } & Frequency(f) & Persentase (\%) \\
\hline \multirow{3}{*}{ Age } & Elderly (60-74) & 343 & 73.9 \\
& Old (75-90 tahun) & 117 & 25.2 \\
Gender & Very Old (>90 tahun) & 4 & 0.9 \\
& Male & 208 & 44.8 \\
Tribe & Female & 256 & 55.2 \\
Education & Java & 458 & 98.7 \\
& Antoher tribe & 6 & 1.3 \\
Marital Status & High education & 103 & 22.2 \\
& Low educatio & 361 & 77.8 \\
\multirow{4}{*}{ Residence } & Married & 286 & 61.6 \\
Location & Widow/Widower & 161 & 34.7 \\
& Not Married & 17 & 3.7 \\
Living Together & Rural & 364 & 78.4 \\
& Urban & 100 & 21.6 \\
& Nos & 409 & 88.1 \\
\hline
\end{tabular}

The final results of this research is in the form of causal modeling, obtained by doing several steps before computation, namely parameter setting. Parameter settings in the S3C-Latent method include determining the subset (S), the number of iterations (I), the number of models to be evaluated (P), the crossover probability, and the mutation probability (C) [25]. In this research, the setting parameters used were $\mathrm{S}=150, \mathrm{I}=50, \mathrm{P}=150, \mathrm{C}=0.45$ and $\mathrm{M}=0.01$. The researcher also adds a constraint parameter to this research provided that ADLs do not cause anything.

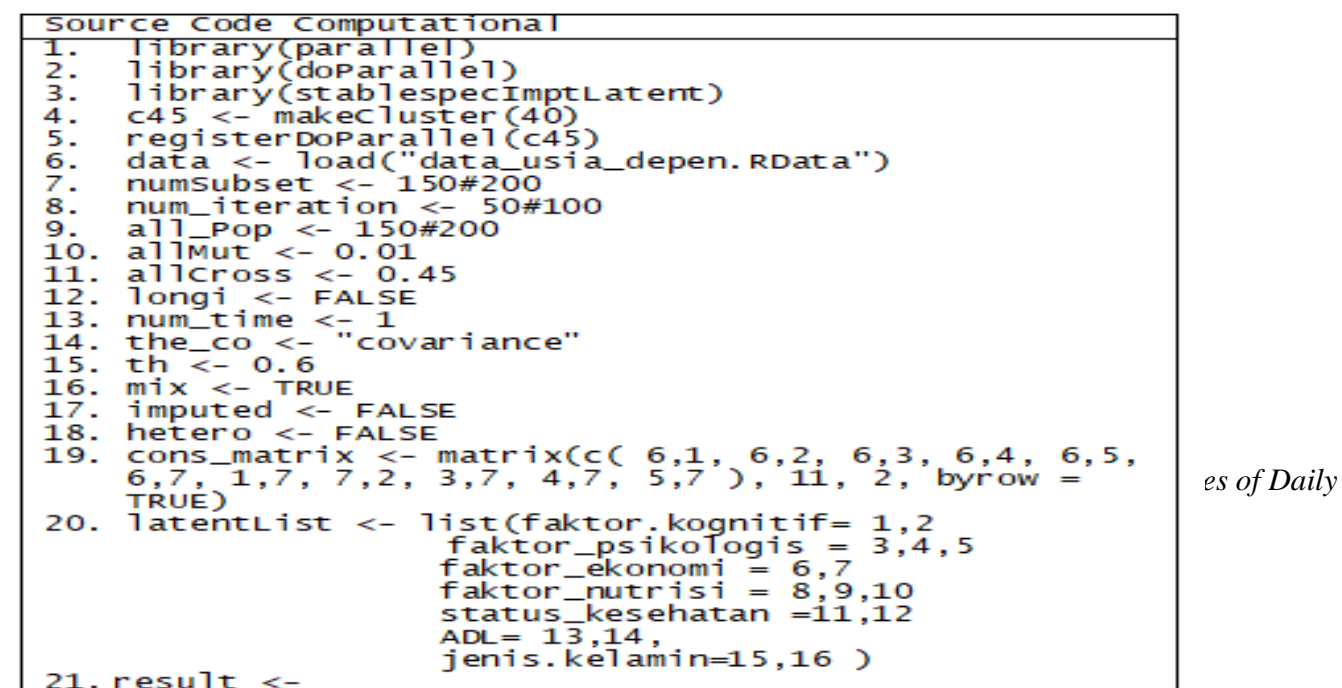


Fig 2. Computational Pseudocode

The All data that have been computed, the results will be analyzed in the form of a stability graph based on the S3C-Latent method. The stability graph in this computation result has three lines consisting of blue lines showing edge stability, green lines showing causal path stability with a length of one, and red lines showing causal path stability for more than one length. The results of this analysis can be seen in

Fig. 3. Causal Stability Graphand

Fig. 4. Association Stability Graph
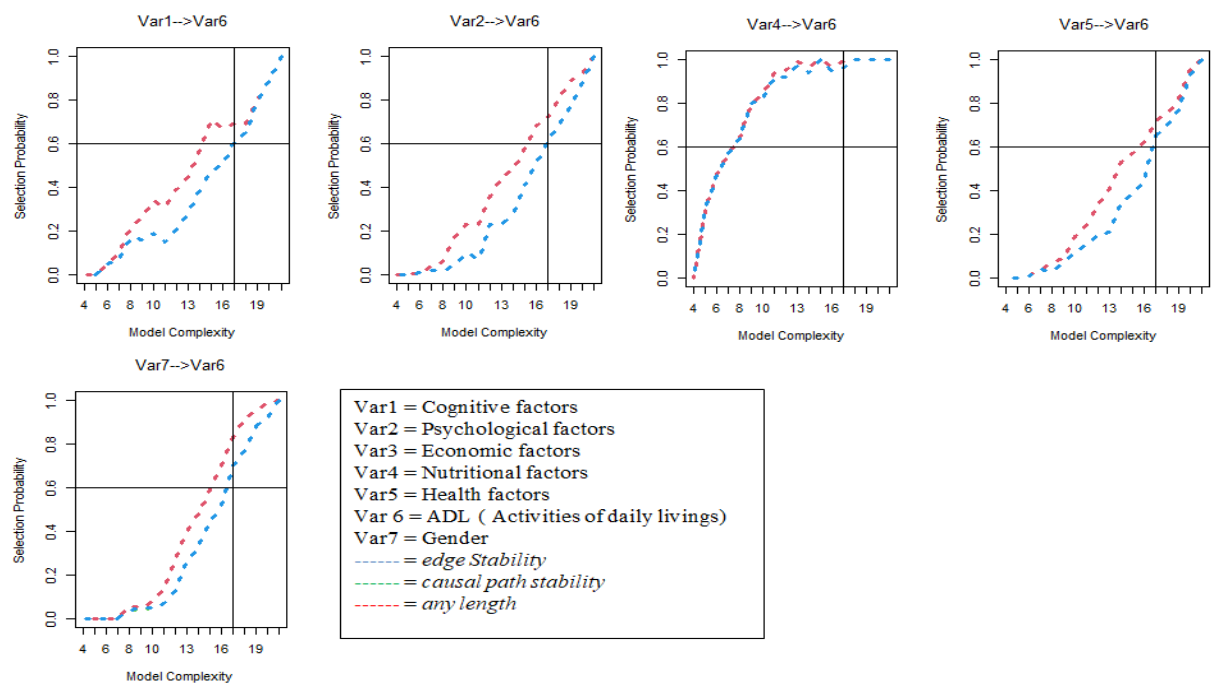

Var1 $=$ Cognitive factors Var2 $=$ Psychological factors Var $3=$ Economic factors Var $4=$ Nutritional factor
Var $5=$ Health factors Var $6=$ ADL (Activities of daily livings) $\operatorname{Var} 7=$ Gender

$=$ edge Stability

= causal path stabilit

$=$ anylength

Fig. 3. Causal Stability Graph

Based on

Fig. 3. Causal Stability Graphrepresents the independent variables on the dependent variable for which a cause-and-effect relationship is sought. The factor stability graph shows five causal relationships that affect the independence of the elderly in ADLs, namely cognitive factors (var1), psychological factors (var2), nutritional factors (var4), health factors, and gender (var7). This causal relationship can be seen by finding the best model which has only a little complexity (parsimonious). The best models are marked with a red line (----) hat crosses that 0.6 threshold value and have models with minimal complexity.
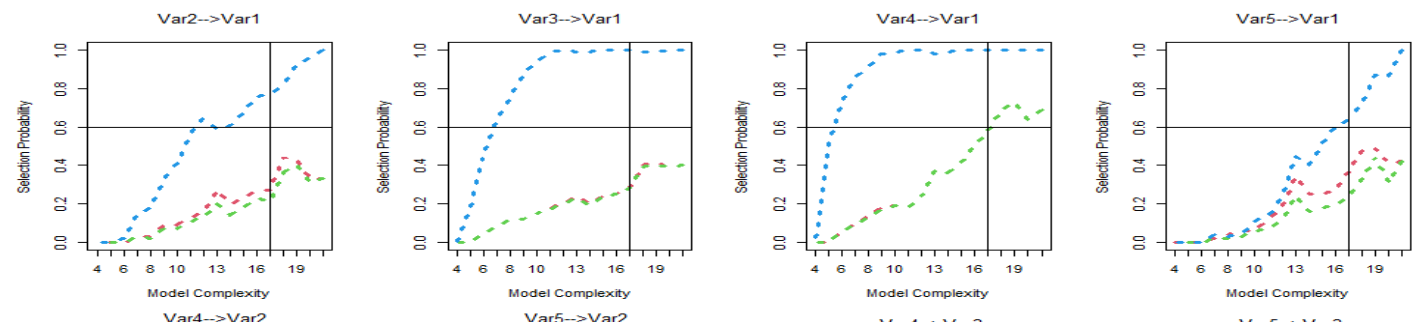
Fig. 4. Association Stability Graph

Based on

Fig. 4. Association Stability Graphshows that there is no causal relationship but found a strong indirect association between variables. The association relationship shows that there is a relationship between two variables, but the direction of the relationship cannot be determined. This can be seen from the graph that those that meet the threshold criteria are depicted by using a blue color line (---) which indicates an association relationship between these variables, while a green line (---) which indicates a causal relationship but does not meet a predetermined threshold value.

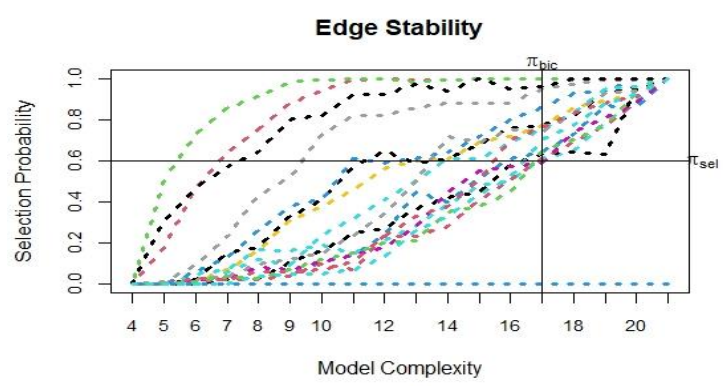

Fig. 5. Edge Stability Graph

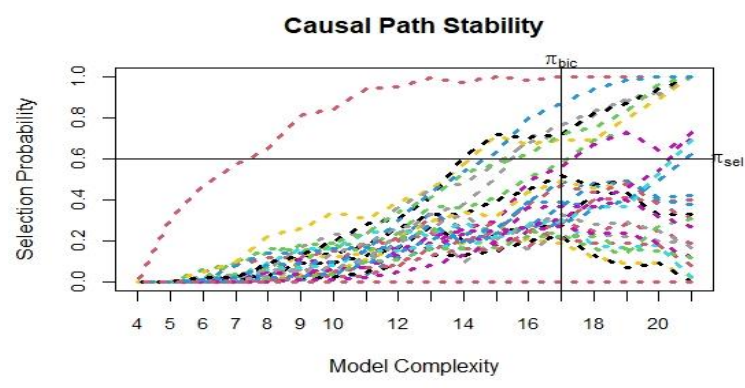

Fig. 6. Causal Path Stability Graph

Based on Fig. 5. Edge Stability Graphand

Fig. 6. Causal Path Stability Graph it can be seen that edge stability and causal path stability in this research with a value of $\pi_{s e l}=0.6$ and $\pi_{b i c}=17$. Each edge stability graph line represents the side between a pair of variables. Edge stability takes into account all relationships regardless of the direction of the relationship. Each causal path stability graph line represents a causal path of length from one variable to another. Causal path stability takes into account the causal relationships in a certain number and frequency. Fig 5 shows that there are 11 relevant edges on the upper left side, while Fig. 6. Causal Path Stability Graph shows that there are 5 causal path variables. The model obtained to represent the structure of the relationship between variables is shown in 
Fig. 7. The Causal Model of Independence Factors Elderly in Activities of Daily Livings

\section{Using S3C-Latent Algorithm}

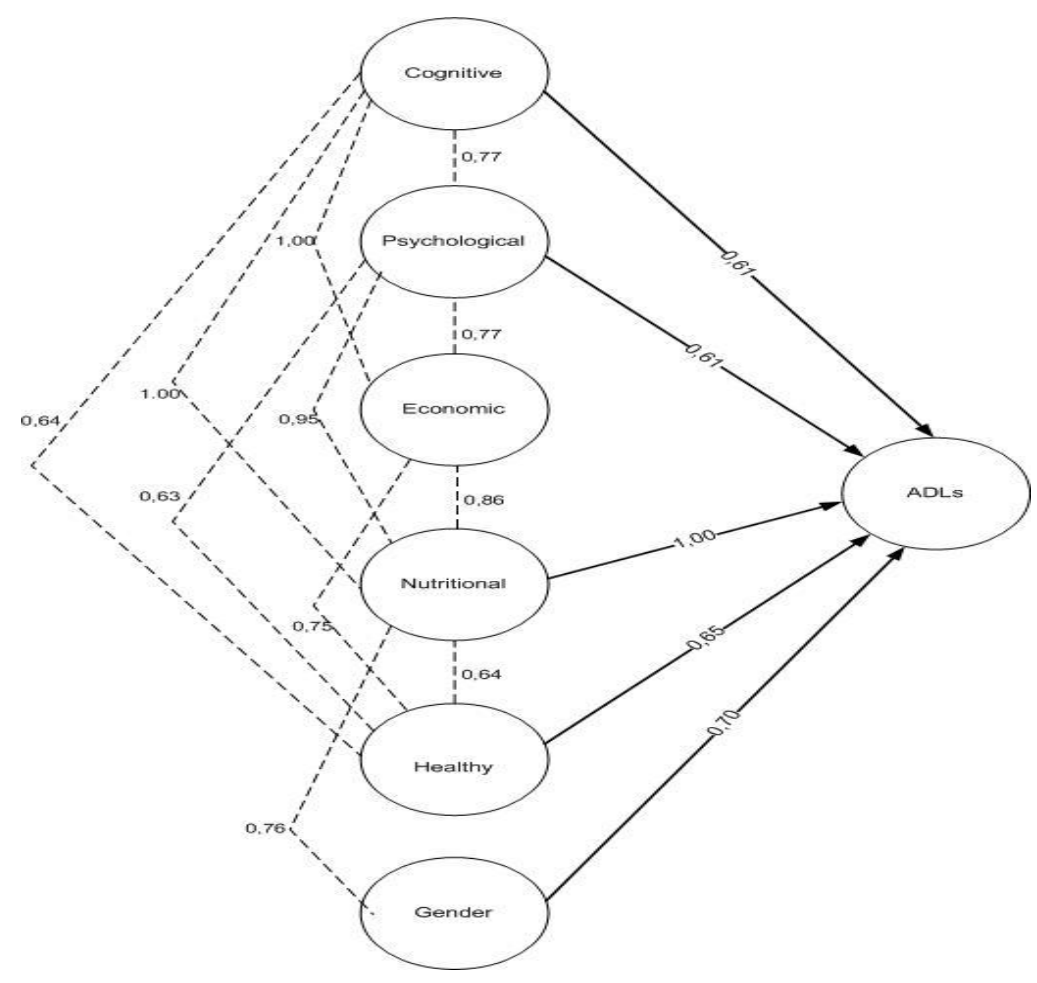

Fig. 7. The Causal Model of Independence Factors Elderly in Activities of Daily Livings Using S3C-Latent Algorithm

Based on

Fig. 7. The Causal Model of Independence Factors Elderly in Activities of Daily Livings, this research found a causal relationship and Indirect association between the factors that influence the independence of the elderly in ADLs. The causal relationship obtained is between the independence factors of the elderly in ADLs which are influenced by 5 factors including cognitive, psychology, nutrition, health, and gender marked with a line arrow. Furthermore, the indirect associations found were; cognitive with psychology, cognitive with economics, cognitive with nutrition, cognitive with health, psychology with economics, psychology with nutrition, psychology with health, economics with nutrition, an economy with health, nutrition with health, then nutrition and gender. The association is shown by the dashed line shown. The most prominent relationship in this research is the causal relationship between nutritional factors and ADLs with a reliability score of 1 .

We implement the results of this research into Shiny web so that it can be used by health workers to serve as a reference to see the relationship of the factors that affect the independence of the elderly. This Shiny web also includes an explanation of the results of the research which can be used as a reference and consideration for health workers in making decisions regarding appropriate therapy for elderly care so that the independence of the elderly is maintained. The web tool contains several features which include data and methods, computation flow, computation results, and visualization. An example of the source code used to design a Shiny web can be seen below.

Example of shiny web Source Code

Tibrary(shiny)

library(tidyverse)

library (shinydashboard)

library (rvest)

library(DT)

Nurhaeka Tou et.al (Causal Relations of Factors Representing the Elderly Independence in Doing Activities of Daily Livings Using S3C-Latent Algorithm) 
Tibrary(pTotTy)

Tibrary (ggplot2)

\# Define UI for application that draws a histogram

ui<-fluidpage(

dashboardPagec skin = "blue",

dashboardHeader(title = "APP Shiny Kemandirian Lansia", titlewidth $=650$ ), dashboardsidebar

sidebarmenu(id = 'sidebarmenu',

\# first menu item

menuItem("Apa itu kemandirian ?", tabName = "penjelasan1", icon =

icon("question-circle")),

\# second menu item with 2 sub menus

menuItem ('Data and Metode',

menusubItem ('Data', tabName $=$ 'data')

menuSubItem ('Metode', tabName = 'metode'))

menuItem("A7ur Komputasi", tabName = "alur"),

menuItem('Hasil Komputasi'

menuSubItem ('Causal and Edge Stability', tabName = 'edge', icon =

icon ('line-chart'))

menuSubItem ('Kausal and Asosiasi Graph', tabName = 'kausal', icon = icon('Tine-chart'))), menuItem("Visualisasi", tabName $=$ "db", icon $=i \operatorname{con}(' 1$ ine-chart'))) ).

The web design begins by installing several libraries that will be used. Shiny library for designing shiny web using R programming and shinydashboar library for designing shiny look. The appearance of the web shiny tool can be seen in Fig. 9. Visualization on R shinyFig. 9. Visualization on R shiny

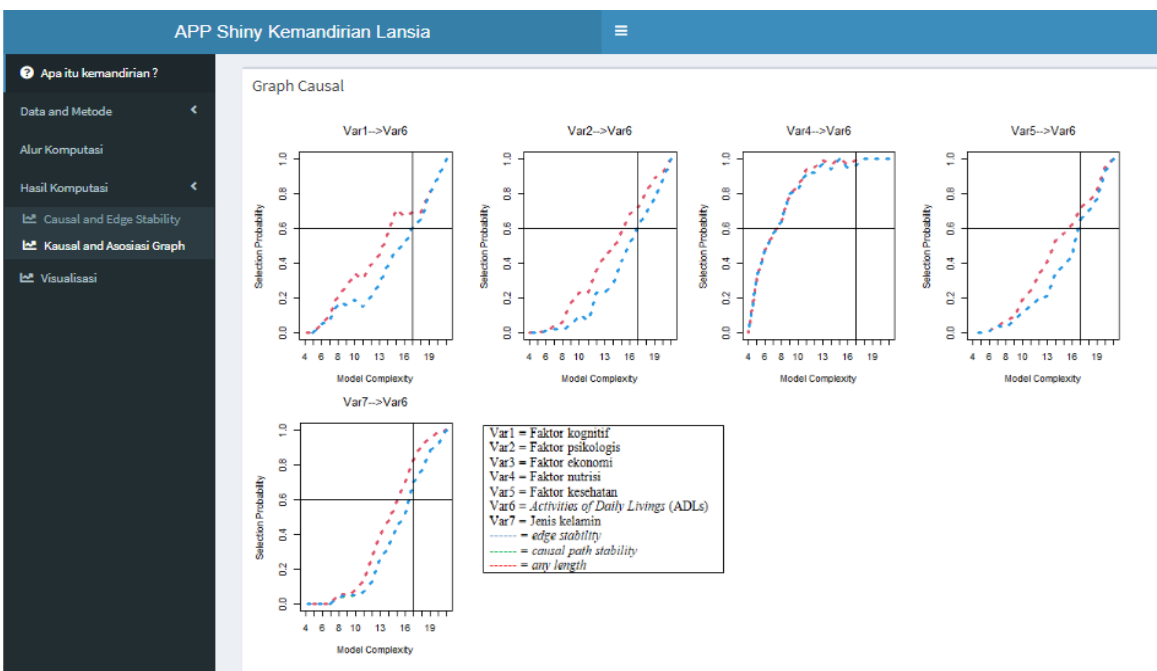

Fig 8. Graph Causal on R Shiny

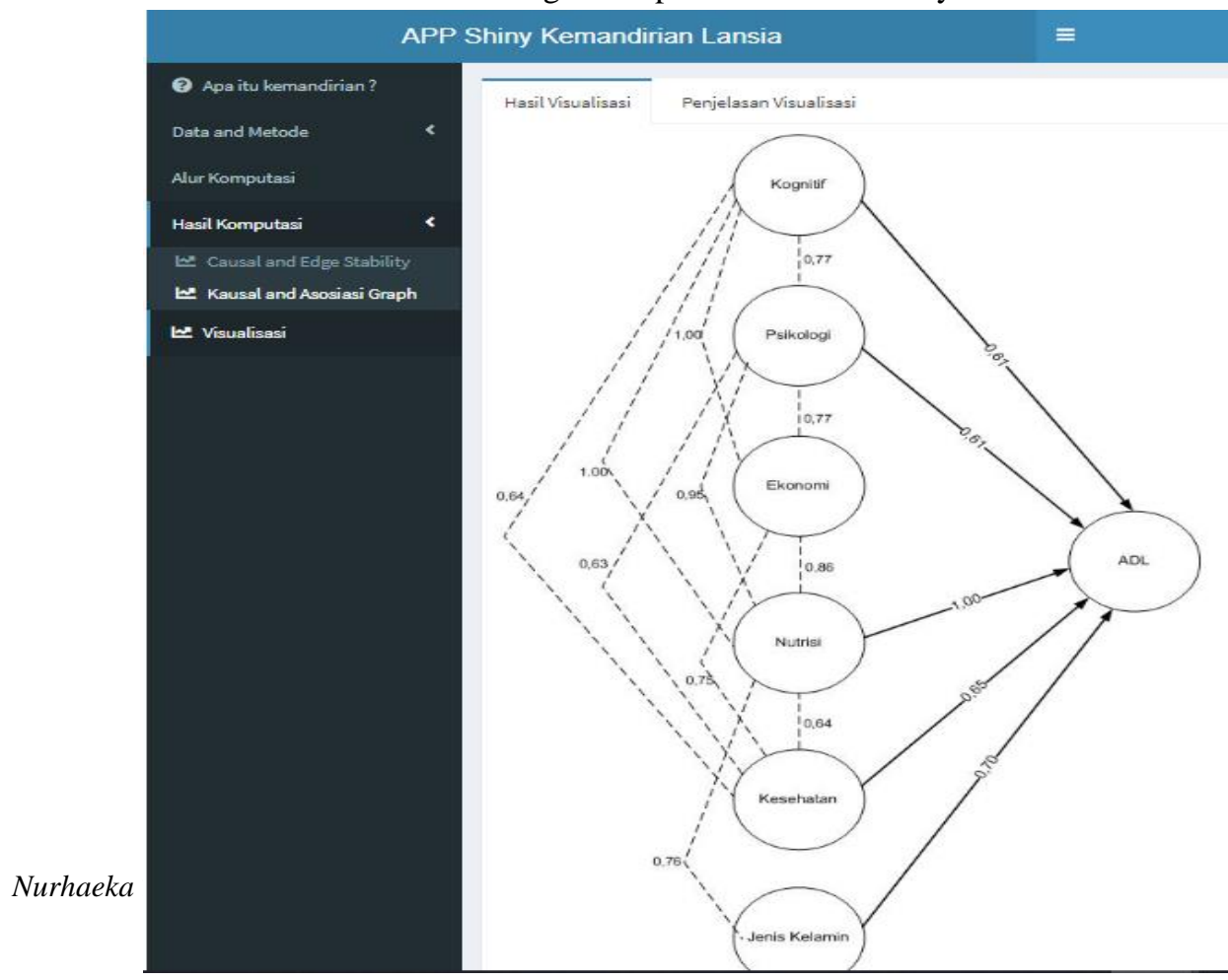


Fig. 9. Visualization on R shiny

\section{B. Discussion}

We disseminate the results of the research by developing an Shiny App so that it can be used by health workers to be used as a reference in seeing the causal relationship of the factors that affect the independence of the elderly in doing ADLs. That way health workers are more focused on handling and caring for the elderly based on the factors that trigger the decline in elderly independence. This Shiny App also contains explanations of the research results obtained to be used as a support in making decisions about appropriate therapy for elderly care so that their independence is maintained. The results of this research differed from some previous studies $[12,13,14,28,29]$, which generally only focused on correlation analysis and prediction of elderly independence factors. Meanwhile, the results of this research were able to identify the direction of the cause-and-effect relationship of the independent factors of the elderly in performing ADLs. However, the limitation of this research only focuses on seeing the causal relationship of the elderly independence factor on gender demographic characteristics. The hope is that further research can explore other models of causal relationships by adding other demographic characteristics.

\section{Conclusion}

The results of the causal modeling research of the factors that influence the independence of the elderly in carrying out their daily activities show that the S3C-Latent method can be used to model the causal relationship of the independence factors of the elderly. The research results found a causal relationship was found on the independence of the elderly in conducting ADLs caused by cognitive, psychological, nutritional, health, and gender factors. Besides, in this research, there was no causal relationship between factors but found eleven associations between factors that could indirectly affect the independence of the elderly in ADLs. This association relationship shows that there is a relationship between the two factors but the direction of the relationship cannot be determined. The obtained model generally shows a high-reliability score. Researchers hope that the model obtained can be a scientific reference, practitioners at large and help health workers and elderly cadres in providing appropriate interventions for elderly patients. The suggestion from researchers for further research is to explore the same model but with the addition of other demographic characteristics.

\section{Acknowledgment}

Thanks UGM Health and Demographic Surveillance System (HDSS) for allowing the use of the elderly self-reliance dataset and the Informatics Department Grant that has funded this research.

\section{References}

[1] R. T. S. Arum and Mulyaningsih, "Tingkat Depresi Memengaruhi Kemandiirian Activity Daily Livings (ADL) Lansia,” GASTER, vol. XV, no. 2, pp. 121-131, 2017.

[2] Kemenkes, Situasi dan Analisis Lanjut Usia dan Gambaran Kesehatan Lanjut Usia di Indonesia. Badan Pusat Statistik, 2019.

[3] WHO, World Population Ageing 2019. 2019.

[4] A. Kurniawan, F. I. Kesehatan, and U. M. Surakarta, "Hubungan Tingkat Kecemasan dengan Tingkat Instrumental Activities of Daily Livings Lansia dengan Hipertensi di Puskesmas Penumping," Kesehat. Masy., 2018.

[5] R. Goto, N. Tanaka, T. Kanamori, T. Nagasawa, S. Koseki, and H. Yanagi, "Independence in Activities of Daily Living in Elderly People with Disuse Syndrom New Learnging Strategy in Outpatient Physical Therapy," Physiotherapy, vol. 101, pp. 471-472, 2015. 
[6] Surti, E. Candrawati, and Warsono, "Hubungan antara Karakteristik Lanjut Usia dengan Pemenuhan Kebutuhan Aktivitas Fisik Lansia di Kelurahan Tlogomas Kota Malang," Nurs. News (Meriden)., vol. 2, pp. 103-111, 2017.

[7] H. Xie, P. Chen, L. Zhao, X. Sun, and X. Jia, "Relationship between activities of daily living and depression among older adults and the quality of life of family caregivers," Front. Nurs., vol. 5, no. 2, pp. 97-104, 2018.

[8] M. Kitamura, K. P. Izawa, M. Yaekura, Y. Mimura, H. Nagashima, and K. Oka, "Differences in nutritional status and activities of daily living and mobility in elderly hospitalized patients with heart failure," ESC Hear. Fail., vol. 6, no. January, pp. 344-350, 2019.

[9] S. Rohaedi, S. T. Putri, and A. D. Karimah, "Tingkat Kemandirian Lansia dalam Activities Daily Living Di Panti Sosial Tresna Werdha Senja Rawi," Pendidik. Keperawatan Indones., vol. 2, no. 1, pp. 16-21, 2016.

[10] L. Pei, X. Zang, Y. Wang, Q. Chai, and J. Wang, "Factors Associated with Activities of Daily Living Among the Disabled Elders with Stroke," Int. J. Nurs. Sci., vol. 3, no. 1, pp. 29-34, 2016.

[11] M. E. Mlinac and M. C. Feng, "Assessment of Activities of Daily Living, Self-Care, and Independence,” Arch. Clin. Neuropsychol., vol. 31, no. July, pp. 506-516, 2016.

[12] Kodri and E. Rahmayati, "Faktor yang Berhubungan dengan Kemandirian Lansia dalam Melakukan Aktivitas Sehari-Hari,” J. Keperawatan, vol. XII, no. 1, pp. 81-89, 2016.

[13] L. Marlita, R. Saputra, and M. Yamin, "Faktor-Faktor yang Memengaruhi Tingkat Kemandirian Lansia Dalam Melakuakn Aktivities of Daily Living (ADL) Di UPT PSTW Khusnul Khotimah,” $J$. Keperawatan Abdurrab, pp. 64-68, 2018.

[14] S. Wahyuni, "Faktor-Faktor yang Berhubungan dengan Kemandirian Lansia dalam Melakukan ADLs Di Kabupaten Sleman Yogyakarta," Universitas Gadjah Mada, 2019.

[15] R. Rahmadi, P. Groot, and T. Heskes, "Stable specification search in structural equation model with latent variables," C. Trans. Intell. Syst. Technol, vol. vol.10, no, pp. 1-19, 2019.

[16] R. Rahmadi, "Finding stable causal structures from clinical data," pp. 63-78, 2019.

[17] E. Madyaningrum, Y. Chuang, and K. Chuang, "Factors associated with the use of outpatient services among the elderly in Indonesia," BMC Health Serv. Res., vol. 8:707, pp. 1-9, 2018.

[18] M. F. Folstein, S. E. Folstein, and P. R. Mchugh, "Mini-Mental State,” Psychiat, vol. 12, pp. 1891198,1975

[19] T. L. Brink and Yesavage, "Development and Validation of A Greatric Depression Screening Scale : A Preliminary Report," J. Psychal, vol. 17, no. I, pp. 37-49, 1983.

[20] G. Topa, S. Zappalà, G. Giorgi, and U. Europea, "Financial Management Behavior Among Young Adults : The Role of Need for Cognitive Closure in a Three-Wave Moderated Mediation Model," Front. Psychol., vol. 9, no. November, pp. 1-10, 2018.

[21] H. Villars, C. Hospitalier, U. De Toulouse, M. Soto, Y. Guigoz, and J. E. Morley, "Overview of the MNA - Its history and challenges," J. Nutr. Health Aging, vol. 10, no. 6 November, pp. 456-465, 2006.

[22] D. N. Aini and W. Puspitasari, "Hubungan Fungsi Kognitif dengan Kualitas Hidup pada Lansia Di Kelurahan Barusari Kecamatan Semarang Selatan,” J. Keperawatan, vol. 7, pp. 6-12, 2016.

[23] L. Prabhaswari and N. A. Luh, "Gambaran Kejadian Depresi pada Lanjut Usia di Wilayah Kerja Puskesmas Petang I Kabupaten Bandung Bali 2015,” J. Med. Udayana, vol. 7, no. 1, pp. 2-7, 2015.

[24] S. M. Kiik, S. Junaiti, and H. Permatasari, "Peningkatan Kualitas Hidup Lanjut Usia Di Kota Depok dengan Latihan Keseimbangan,” J. Keperawatan Indones., vol. 21, no. 2, pp. 109-116, 2018.

[25] A. Masitah and D. Febriana, "Status Kesehatan dan Evaluasi Nutrisi pada Lansia," JIM FKEP, vol. III, no. 3, pp. 359-364, 2018.

[26] Y. K. Sari and E. T. Susanti, "The correlation of Sexes and Hypertention of Elderly in Nglegok Public Health Centre Kabupaten Blitar," J. Ners dan Kebidanan, vol. 3, pp. 262-265, 2016.

[27] M. Diana et al., "Subjective Cognitive Decline, APOE $\varepsilon 4$, and Incident Mild Cognitive Impairment in Men and Women," vol. 11, pp. 221-230, 2019.

[28] M. Lee, Y. Jang, and W. C. Id, "How do impairments in cognitive functions affect activities of daily living functions in older adults ?," J. Pone, pp. 1-14, 2019.

[29] L. Rue, J. Garry, Y. Haaland, J. Wayne, and J. Chiulli, "Nutritional status and cognitive functioning ag ing sam pie : a 6-y reassessment1 in a normally," Am J Cin Nutr, vol. 65, no. March, pp. 20-29, 2018. 